\title{
Bioactivities of Eriobotrya japonica (Thunb.) Lindl. Leaf and Its Triterpenes
}

Takuhiro Uto, Nguyen Huu Tung, Kensuke Nakajima, Tomoe Ohta, Shigeru Oiso, Hiroko Kariyazono and Yukihiro Shoyama*

Department of Pharmacognosy, Nagasaki International University, Japan

*Corresponding author: Yukihiro Shoyama, Department of Pharmacognosy, Faculty of Pharmaceutical Sciences, Nagasaki International University, Japan, Tel: +81-956205740; E-mail: shoyama@niu.ac.jp

Received date: Mar 10, 2017; Accepted date: Mar 25, 2017; Published date: Mar 28, 2017

Copyright: ( 2017 Shoyama Y, et al. This is an open-access article distributed under the terms of the Creative Commons Attribution License, which permits unrestricted use, distribution, and reproduction in any medium, provided the original author and source are credited.

\begin{abstract}
The dried leaves of Eriobotrya japonica have traditionally been widely used to treat various diseases, such as chronic bronchitis, cough, inflammation, skin disease, and diabetes. Our previous studies have reported several functions and their molecular mechanisms of E. japonica leaf extract and triterpenes contained in the extract. In this review article, we focus on the effects of $E$. japonica leaf extract and triterpenes on inflammatory mediators, proliferation of cancer cells, and ghrelin production. 1) The leaf extract of $E$. japonica suppressed inflammatory mediators including nitric oxide (NO) and prostaglandin $\mathrm{E}_{2}\left(\mathrm{PGE}_{2}\right)$ production in lipopolysaccharide (LPS)-stimulated RAW264 murine macrophage cells. The anti-inflammatory properties of $E$. japonica leaf extract resulted from inhibition of inducible nitric oxide synthase (iNOS) and cyclooxygenase-2 (COX-2) expressions through downregulation of nuclear factor-KB (NF-KB) activation and mitogen-activated protein kinases (MAPK) phosphorylation. 2) E. japonica leaves contain triterpenes such as corosolic acid, ursolic acid, maslinic acid, and oleanolic acid. Corosolic acid exterted the strongest anti-proliferative activity in human leukemia cell lines. Moreover, corosolic acid induced apoptosis mediated by mitochondrial dysfunction and caspase activation. 3) Ghrelin is an appetite-stimulating peptide hormone with an octanoyl modification at serine 3 that is essential for its orexigenic effect. Our investigation of triterpenes from E. japonica, corosolic acid, oleanolic acid, and ursolic acid suppressed octanoylated ghrelin levels in AGS-GHRL8 cell line, which produces octanoylated ghrelin in the presence of octanoic acid, without decreasing transcript expression of ghrelin O-acyltransferase (GOAT) or furin.
\end{abstract}

Keywords: Eriobotrya japonica; Triterpenes; Anti-inflammation; Apoptosis; Ghrelin suppression

\section{Introduction}

Eriobotrya japonica (Thunb.) Lindl. belongs to the Rosaceae family. This species is an evergreen fruit tree native to China that is approximately $10 \mathrm{~m}$ high. The tree typically blooms in winter (Figure 1A) and bears a fruit in early summer known as the loquat in Japan (Figure 1B). The dried leaves of E. japonica are used in Japanese Kampo medicines and Traditional Chinese Medicines (TCM) for chronic bronchitis, cough, skin disease, inflammation, and diabetes.
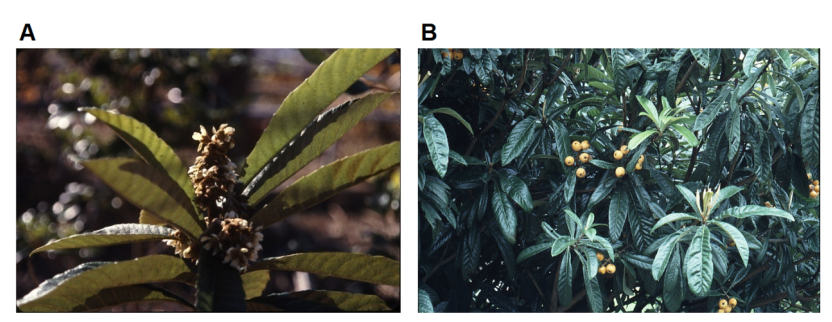

Figure 1: Blooms (A) and fruits (B) of Eriobotrya japonica.

Previous phytochemical investigations have demonstrated that $E$. japonica leaves contain triterpenes, sesquiterpenes, flavonoids, tannins, and amygdalin [1,2]. Among them, novel biological properties of triterpenes, such as the attenuation of glycosylated serum protein, total cholesterol, and triglyceride level in diabetic mice have been reported [3]. The total triterpenes of E. japonica leaves reduced the production of inflammatory cytokines from alveolar macrophages through inhibition of nuclear factor- $\kappa \mathrm{B}(\mathrm{NF}-\kappa \mathrm{B})$ activation in a rat model of chronic bronchitis [4]. In addition, triterpenes of E. japonica leaves suppressed 12-O-tetradecanocylphorbol-13-acetate-induced inflammation in mice [5]. Moreover, the polyphenols, such as flavonoids and their glycosides, and proanthocyanidins, have cytotoxicity against human oral tumor cells [6]. Kikuchi et al. found that apoptotic cell death in human leukemia cells was caused by a coumaroyl triterpenes [7]. Liu et al. reviewed the biological activities of flavonoids, proanthocyanidins, and triterpenes in E. japonica leaves [8].

In our ongoing studies related to the induction of apoptosis in human cancer cell lines caused by natural products, we identified several active components, such as crocin in saffron [9], alkanin in Alkanna tinctoria [10], saikosaponin a in Bupleurum falcatum [11], quassinoids in Eurycoma longifolia [12], curcuminoid in Alnus japonica [13], and coumarin derivatives in Mammea siamensis [14]. Furthermore, fingerprinting has demonstrated that $E$. japonica leaves contain triterpenes as major components [15].

In this review, we will concentrate on reviewing the bioactivities of leaf extract of E. japonica and triterpenes contained in the extract. At first, we describe the anti-inflammatory properties of $E$. japonica leaf extract. Next, we introduce the effects of triterpenes of E. japonica leaves on proliferation of cancer cells, and show the mechanism of action of corosolic acid-induced apoptosis. Furthermore, we describe the effects of the triterpenes on ghrelin production and its potential 
Citation: $\quad$ Takuhiro Uto, Nguyen Huu Tung, Kensuke Nakajima, Tomoe Ohta, Shigeru Oiso, Hiroko Kariyazono and Yukihiro Shoyama (2017) Bioactivities of Eriobotrya japonica (Thunb.) Lindl. Leaf and Its Triterpenes. J Pharmacogn Nat Prod 3: 134. doi: $10.4172 / 2472-0992.1000134$

molecular mechanism. In conclusion section, we discuss the possibility of $E$. japonica leaf on the potential resource as natural medicines.

\section{Anti-Inflammatory and Mechanism of Action of Eriobotrya japonica Leaf Extract}

Activation of macrophages and monocytes occurs in the inflammatory process. An inflammatory stimulus, such as Lipopolysaccharide (LPS), an endotoxin derived from cell walls of Gram-negative bacteria, can activate macrophages to produce inflammatory mediators, including nitric oxide $(\mathrm{NO})$, prostaglandin $\mathrm{E}_{2}$ $\left(\mathrm{PGE}_{2}\right)$, and pro-inflammatory cytokines $[16,17]$. NO has an important role in regulation of many physiological functions, such as vasodilatation, neurotransmission, and inflammation $[18,19]$. NO is produced by oxidation of L-arginine catalyzed by NO synthase (NOS). In the NOS family, inducible NOS (iNOS) is induced by specific inflammatory stimuli, such as LPS and inflammatory cytokines, in various cell types including macrophages [20]. iNOS actively catalyzes formation of an excess $\mathrm{NO}$, which has a key role in inflammation and carcinogenesis $[21,22]$. COX-2 is also induced by pro-inflammatory stimuli in various cell types such as macrophages and epithelial cells $[23,24]$. COX-2 and excess prostaglandins (PGs) including $\mathrm{PGE}_{2}$ have important roles in multiple epithelial cancers, such as colon carcinoma [25]. Thus, excess $\mathrm{NO}$ and $\mathrm{PGE}_{2}$, which are derived from iNOS and COX-2, respectively, are potent inflammatory mediators.

In this section, we introduce the inhibitory actions of crude leaf extract of E. japonica on the production of $\mathrm{NO}$ and $\mathrm{PGE}_{2}$ as well as iNOS and COX-2 expressions. Furthermore, the molecular mechanisms underlying these inhibitions were also described.

\section{Effects of Eriobotrya japonica leaf extract on NO and $\mathrm{PGE}_{2}$ productions and iNOS and COX-2 expressions}

The leaf extract of E. japonica significantly attenuated LPS-induced $\mathrm{NO}$ (Figure 2A) and $\mathrm{PGE}_{2}$ in LPS-stimulated RAW264 murine macrophage cells (Figure 2B) [26]. In response to LPS, the protein expressions of iNOS and COX-2 were markedly upregulated, and $E$. japonica leaf extract inhibited these inductions (Figure 2C) [26]. Moreover, iNOS and COX-2 mRNA expressions correlated with their protein levels (Figure 2D) [26]. Thus, the inhibitory effects of $E$. japonica extract on $\mathrm{NO}$ and $\mathrm{PGE}_{2}$ production were caused by decreased protein and mRNA expression of iNOS and COX-2.

\section{Effect of Eriobotrya japonica leaf extract on degradation of I $\kappa \mathrm{B}-\boldsymbol{\alpha}$ and NF- $\kappa \mathrm{B}$ activation}

NF- $\kappa \mathrm{B}$ is known to activate iNOS and COX-2 [24,27]. In unstimulated cells, NF- $\kappa B$ is sequestered in the cytosol by its inhibitor I $\mathrm{B}$, which is phosphorylated by LPS stimulation, ubiquitinated, and then rapidly degraded by the $26 \mathrm{~S}$ proteosome, all of which leads to release of a functional NF- $\kappa B$ [28]. Activated NF- $\kappa$ B translocates to the nucleus and activates expression of the iNOS and COX-2 genes. As shown in Figure 3A, E. japonica leaf extract inhibited LPS-induced I $\kappa-\alpha$ degradation [26]. In addition, E. japonica leaf extract reduced the DNA binding activity of $\mathrm{p} 65$, a critical subunit of NF- $\kappa \mathrm{B}$, to the consensus sequences (Figure 3B) [26]. These data suggest that leaf extract of $E$. japonica suppressed activation of NF- $\mathrm{KB}$ at least partly through inhibition of IкB- $\alpha$ degradation.
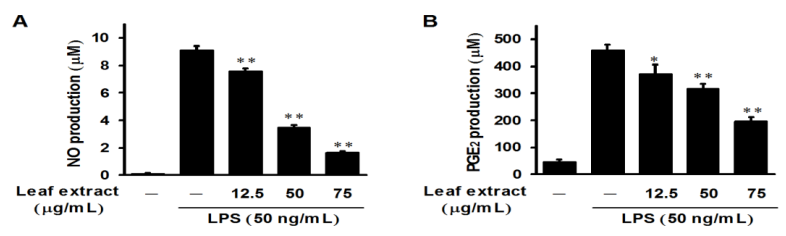

c
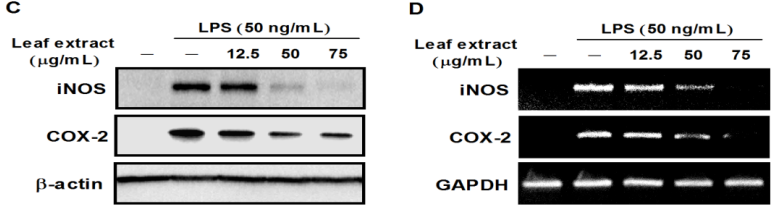

Figure 2: Effect of Eriobotrya japonica leaf extract on LPS-induced $\mathrm{NO}(\mathrm{A})$ and $\mathrm{PGE}_{2}$ (B) production and protein (C) and mRNA (D) expressions of iNOS and COX-2. RAW264 cells were treated with the indicated concentrations of Eriobotrya japonica leaf extract for $30 \mathrm{~min}$, and then exposed to LPS $(50 \mathrm{ng} / \mathrm{mL})$ for $12 \mathrm{~h}$. The NO concentration in the medium was measured using Greiss reagent (A). PGE $_{2}$ production was determined using an EIA kit (B). Each value represents the mean $\pm \mathrm{SD}$ of triplicate tests. ${ }^{*} \mathrm{P}<0.05 ;{ }^{* *} \mathrm{P}<0.01$ versus LPS. (C) RAW264 cells were treated with the indicated concentrations of E. japonica leaf extract for $30 \mathrm{~min}$ before incubation with LPS $(50 \mathrm{ng} / \mathrm{mL}$ ) for $12 \mathrm{~h}$. Protein expression levels of iNOS, COX-2 and $\beta$-actin were detected by Western blotting analysis (D) After $6 \mathrm{~h}$ stimulat ion of $E$. japonica leaf extract and LPS, total RNA were prepared and RT-PCR analysis was performed.

\section{E. japonica}

\section{E. japonica}

A

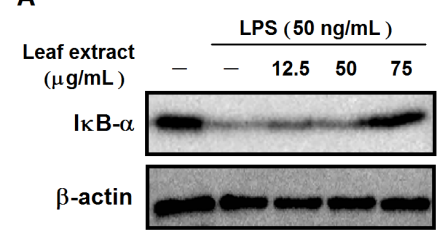

B

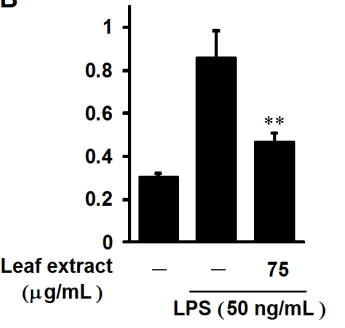

Figure 3: Effect of Eriobotrya japonica leaf extract on LPS-induced IB- degradation (A) and DNA-binding of NF-B (B). RAW264 cells were treated with the indicated concentrations of Eriobotrya japonica leaf extract for $30 \mathrm{~min}$, and then exposed to LPS (50 $\mathrm{ng} / \mathrm{mL}$ ) for $30 \mathrm{~min}$. (A) Protein levels of IкB- $\alpha$ and $\beta$-actin were detected by Western blotting analysis. (B) Nuclear proteins were examined to their ability to bind with the NF- $\kappa \mathrm{B}$ consensus site. The data represent the mean \pm SD of three separate experiments. ${ }^{* *} \mathrm{P}<0.01$ vs. LPS. 
Citation: Takuhiro Uto, Nguyen Huu Tung, Kensuke Nakajima, Tomoe Ohta, Shigeru Oiso, Hiroko Kariyazono and Yukihiro Shoyama (2017) Bioactivities of Eriobotrya japonica (Thunb.) Lindl. Leaf and Its Triterpenes. J Pharmacogn Nat Prod 3: 134. doi: $10.4172 / 2472-0992.1000134$

Page 3 of 9

\section{Effect of Eriobotrya japonica leaf extract on mitogen- activated protein kinases (MAPK) activation}

MAPK, a family of serine/threonine kinases, participate in signal transduction pathways which control intracellular events, including cell growth, differentiation, and control of cellular responses to cytokines and stresses [29]. LPS activates phosphorylation of MAPK, including ERK, p38 kinase, and JNK, and subsequently to enhance iNOS and COX-2 gene expressions [30,31]. E. japonica leaf extract blocked LPS-induced phosphorylation's of ERK, p38 kinase, and JNK, suggesting that $E$. japonica leaf extract effectively inhibited MAPK phosphorylation's (Figure 4) [26].

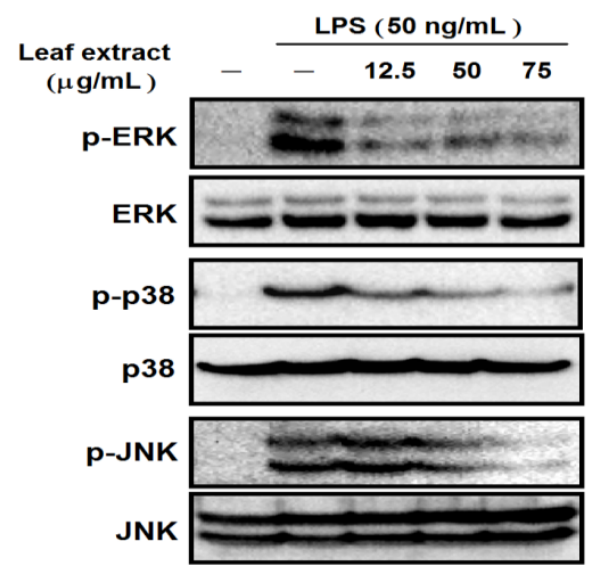

Figure 4: Effect of Eriobotrya japonica leaf extract on LPS-induced MAPKs phosphorylation. RAW264 cells were treated with the indicated concentrations of Eriobotrya japonica leaf extract for 30 $\mathrm{min}$, and then exposed to LPS (50 ng/mL) for $30 \mathrm{~min}$. Protein levels of phosphorylated and total MAPKs were detected by Western blotting analysis.

In conclusion, E. japonica leaf extracts exerted potent antiinflammatory properties by inhibiting iNOS and COX-2 expressions. These inhibitory effects were caused by suppression of NF- $\mathrm{BB}$ activation and MAPK phosphorylations. These findings support the traditional use of E. japonica leaf extract in the treatment of various inflammation-associated diseases.

\section{HPLC Fingerprinting of Triterpenes in Eriobotrya japonica Leaves}

E. japonica leaves contain triterpenes, sesquiterpenes, flavonoids, tannins, and amygdalin [1,2]. Among them, the triterpenes from $E$. japonica leaves might be expected to have potent bioactivities in vivo and in vitro [3]. Thus, quality control of the triterpenes is necessary to maintain consistent and sufficient bioactivities. In our ongoing studies on the quality control of natural products, we have been preparing monoclonal antibodies against pharmacologically active compounds and their application in quality and/or quantity analysis using unique methods, such as eastern blotting, a high-sensitive on-membrane quantitative analysis [32-35]. Since E. japonica leaves contain various kinds of triterpenes, we performed HPLC fingerprinting of triterpenes contained in $E$. japonica leaves to confirm the importance of quality control of E. japonica. As shown in Figure 5A, the HPLC fingerprint of the $\mathrm{CHCl}_{3}$ extract of $E$. japonica leaves indicates the HPLC peak profile of the triterpene constituents in which there are four major components including colosolic acid, ursolic acid, maslinic acid, and oleanolic acid (Figure 5B). The retention times of the ursan-type skeleton components (colosolic acid and ursolic acid) are longer than those of the oleanane group (maslinic acid and oleanolic acid). The retention times of the dihydroxyl group components in the A-ring (maslinic acid and colosolic acid) are shorter than those of the monohydroxyl group components (oleanolic acid and ursolic acid). Therefore, quality control of $E$. japonica leaves for the constant bioactive evidence might be needed to confirm the quantitative determination of oleanolic acid and ursolic acid.
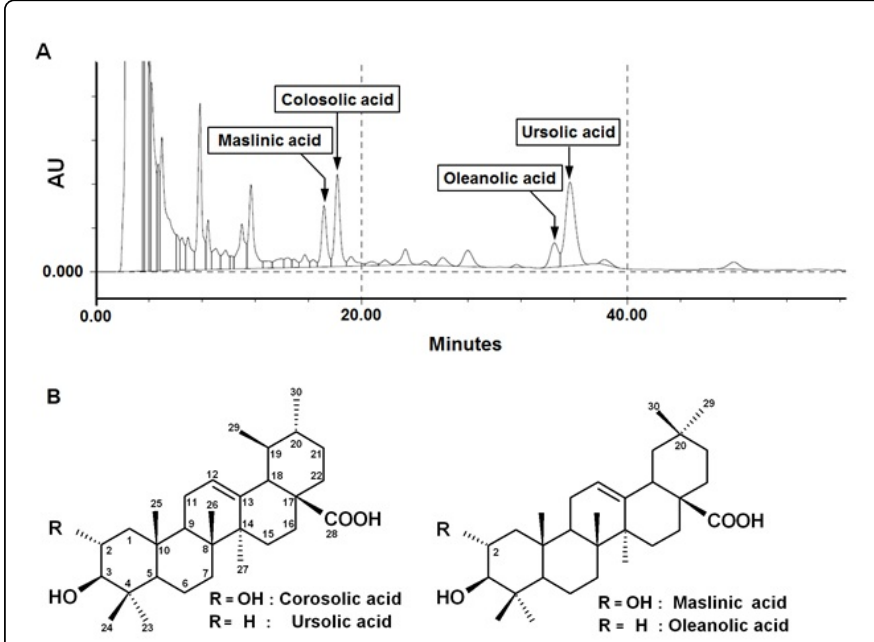

Figure 5: (A) HPLC profile of four triterpenes derived from a $\mathrm{CHCl}_{3}$ extract of Eriobotrya japonica leaves. (B) Chemical structures of colosolic acid, ursolic acid, maslinic acid, and oleanolic acid.

\section{Apoptosis Induction by Triterpenes Contained in Eriobotrya japonica Leaves}

Apoptosis is a highly regulated process that involves the activation of a series of molecular events leading to cell death, which is characterized by cellular morphological changes, chromatin condensation, and DNA fragmentation. Two principal apoptosis pathways, the death receptor (extrinsic) pathway and the mitochondrial (intrinsic) pathway, are well-known [36]. The death receptor pathway is initiated via ligation of the death receptors and their respective ligands, which results in caspase- 8 activation and the induction of downstream caspase- 3 activation via the mitochondrial route, either directly or indirectly [37]. In the mitochondrial pathway, caspase activation is caused by an increase in mitochondrial membrane permeability and the release of cytochrome $c$ into the cytosol. These mitochondrial changes result in the activation of caspase-9, which activates caspase- 3 and triggers irreversible apoptotic cell death [36]. 
Citation: Takuhiro Uto, Nguyen Huu Tung, Kensuke Nakajima, Tomoe Ohta, Shigeru Oiso, Hiroko Kariyazono and Yukihiro Shoyama (2017) Bioactivities of Eriobotrya japonica (Thunb.) Lindl. Leaf and Its Triterpenes. J Pharmacogn Nat Prod 3: 134. doi: $10.4172 / 2472-0992.1000134$

Page 4 of 9

In this section, we describe the anti-proliferative effects of the major triterpenes from E. japonica leaves, i.e., corosolic acid, ursolic acid, maslinic acid, and oleanolic acid, on four human leukemia cell lines. Our data defined the structure-activity correlations of these triterpenes and the molecular mechanism.

\section{Effects of the Four Triterpenes from Eriobotrya japonica Leaves on Cell Proliferation in Human Leukemia and Normal Skin Fibroblast Cell Lines and Their Structure- Activity Correlation}

First, we investigated the effects of corosolic acid, ulsolic acid, maslinic acid, and oleanolic acid on cell proliferation using leukemia cell lines (HL-60, U937, Jurkat, and THP-1) and normal skin fibroblast cell lines (NHSF46 and NB1RGB). Corosolic acid and ursolic acid significantly suppressed cell growth in all leukemia cell lines, whereas maslinic acid and oleanolic acid had weaker effects than those of corosolic acid and ursolic acid (Figure 6A). The inhibitory potency against leukemia cell lines followed the order corosolic acid $>$ ursolic acid $>$ maslinic acid=oleanolic acid. However, remarkably, none of the triterpenes inhibited cell proliferation in NGSF46 and NB1RGB. Thus, we suggest the following structure-activity correlations (Figure 6B): the ursane-type skeleton (corosolic acid and ursolic acid) has a greater suppressive potency than that of the oleanane-type skeleton (maslinic acid and oleanolic acid); the C2-C3 trans-dihydroxyl group in the Aring is important when comparing corosolic acid and ursolic acid; and the C19-C20 trans-dimethyl group in the E-ring is important when comparing corosolic acid and maslinic acid. The results indicated that corosolic acid was the most potent anti-proliferative triterpene against the entire leukemia cell lines tested, whereas it had low cytotoxicity in normal skin fibroblasts. Among four leukemia cell lines, HL-60 and U937 were more sensitive than were Jurkat and THP-1 against the four triterpenes.

\section{Effect of colic acid on apoptosis induction}

We investigated whether the corosolic acid-induced antiproliferative activity against leukemia cells was related to apoptosis induction by analyzing the characteristics of apoptosis, including nuclear morphological changes and DNA fragmentation in HL-60 and U937 cells. In control cells of HL-60 cells, nuclear morphology was normal, but the cells treated with corosolic acid showed chromatin condensation (Figure 7A). Furthermore, corosolic acid led to the appearance of the DNA ladder (Figure 7B). We also analyzed the hypodiploid DNA content (sub-G1 phase), suggesting that corosolic acid increased the percentage of cells in the sub-G1 phase (Figure 7C). Overall, these results clearly indicate that corosolic acid exerted its anti-proliferative effect via induction of apoptotic cell death.

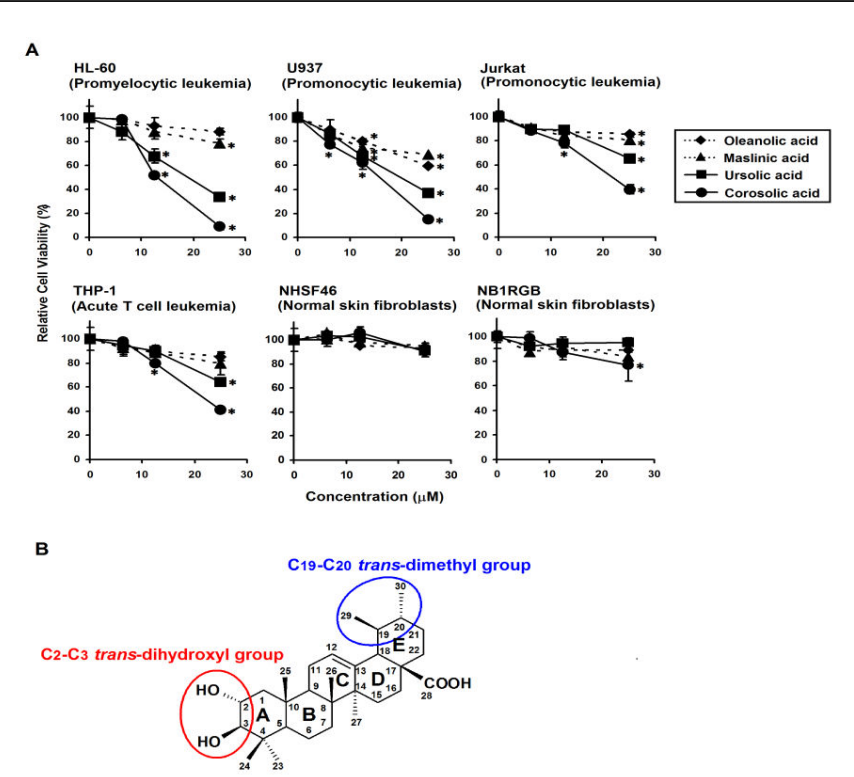

Figure 6: (A) Effects of the four triterpenes on cell proliferation in human leukemia and normal skin fibroblast cell lines. Cells were treated with the indicated compounds at various concentrations for $24 \mathrm{~h}$ and the cell viability was determined using the MTT assay. The data represent the mean \pm S.D. for three individual experiments. ${ }^{*} \mathrm{P}<0.05$ compared with the control group. (B) The structureactivity correlations of the four triterpenes.

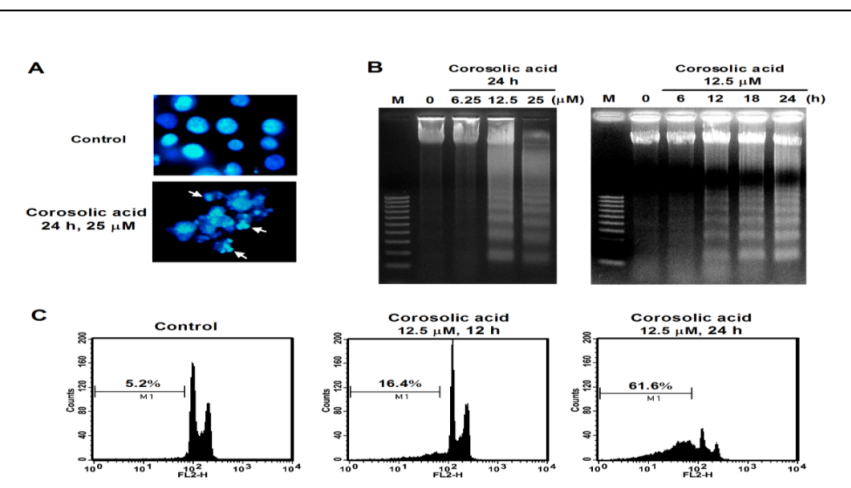

Figure 7: Effect of corosolic acid on apoptosis induction. (A) Induction of chromatin condensation by corosolic acid. HL-60 cells were treated with corosolic acid $(25 \mu \mathrm{M})$ for $24 \mathrm{~h}$ and stained with Hoechst 33258. The nuclear morphology was observed by fluorescent microscopy (magnification $\times 400$ ). (B) Induction of DNA fragmentation by corosolic acid. HL-60 cells were treated with corosolic acid at various concentrations for $24 \mathrm{~h}$, or at $12.5 \mu \mathrm{M}$ for the times indicated, and the DNA fragmentation was analyzed by agarose gel electrophoresis. $\mathrm{M}$ is the 100-bp DNA marker. (C) Increase of the sub-G1 phase cells by corosolic acid. HL-60 cells were treated with corosolic acid $(12.5 \mu \mathrm{M})$ for the times indicated and analyzed by flow cytometry after staining with PI. The data shown are representative of three independent experiments with similar results. 
Citation: $\quad$ Takuhiro Uto, Nguyen Huu Tung, Kensuke Nakajima, Tomoe Ohta, Shigeru Oiso, Hiroko Kariyazono and Yukihiro Shoyama (2017) Bioactivities of Eriobotrya japonica (Thunb.) Lindl. Leaf and Its Triterpenes. J Pharmacogn Nat Prod 3: 134. doi: $10.4172 / 2472-0992.1000134$

Page 5 of 9

\section{Involvement of the caspase cascade in corosolic acid-induced apoptosis}

Caspase- 3 is critical effector caspase and initiates apoptotic damage. Activation of caspase- 3 requires activation of initiator caspases, such as caspase- 8 and -9 [36]. Corosolic acid induced time-dependent activations of caspase-3, -8 , and -9 . Furthermore, PARP cleavage occurred in response to colosolic acid treatment (Figure 8A). Furthermore, corosolic acid-induced DNA fragmentation was abolished by broad caspase inhibitor (z-VAD-FMK) and specific inhibitor against caspase-3 (z-DEVD-FMK), -8 (z-IETD-FMK), and -9 (z-LEHD-FMK) (Figure 8B). These results indicate that corosolic acidinduced apoptosis involves a caspase-dependent pathway in HL-60 cells.

\section{Effect of corosolic acid on mitochondrial dysfunction}

Mitochondrial changes include the loss of the mitochondrial membrane potential $(\Delta \psi \mathrm{m})$ and cytochrome $\mathrm{c}$ release from the mitochondria to the cytosol, which subsequently leads to caspase-9dependent activation of caspase-3 [37]. Cytochrome $c$ is normally located in the intermembrane space of mitochondria, and loss of the $\Delta \psi \mathrm{m}$ causes the release of cytochrome c from mitochondria into the cytosol [37]. Cytochrome $c$ gradually accumulated in the cytosol in response to colosolic acid treatment (Figure 9A). JC-1 is a sensitive mitochondrial membrane potential probe. JC-1 can selectively enter mitochondria depending on the membrane potential, and the JC-1 molecule spontaneously forms J-aggregates that produce intense red fluorescence. Corosolic acid decreased the percentage of red fluorescent cells (Figure 9B). These results indicate that mitochondrial dysfunction is involved in corosolic acid-induced apoptosis in HL-60 cells.

\section{Effect of corosolic acid on Bcl-2 family proteins}

The mitochondrial pathway is mainly regulated by $\mathrm{Bcl}-2$ family proteins, which are divided into the pro-apoptotic proteins (e.g., Bax and Bid) and anti-apoptotic proteins (e.g., Bcl-2 and Bcl-xL) [38]. Bid is a pro-apoptotic member, which is cleaved by caspase- 8 to its active form, truncated Bid (tBid). Corosolic acid cleaved Bid protein to tBid (Figure 10). On the other hand, the anti-apoptotic proteins, Bcl-2 and $\mathrm{Bcl}-\mathrm{xL}$, were unaffected by corosolic acid. Bid activation triggers translocation of cytosolic Bax into mitochondria, which is followed by loss of $\Delta \psi \mathrm{m}$ [39]. Corosolic acid promotes translocation of Bax into mitochondria. Taken together, corosolic acid induces activation of proapoptotic Bid and Bax, which leads to loss of $\Delta \psi \mathrm{m}$ and release of cytochrome $\mathrm{c}$ from mitochondria into the cytosol.

We showed that corosolic acid effectively induced apoptosis in HL-60 cells, which involves the death receptor pathway and the mitochondrial pathway, because corosolic acid induced the activation of caspase-8 and -9. Corosolic acid-induced caspase- 8 activation triggered mitochondrial dysfunction by inducing tBid-mediated Bax activation (Figure 11). These findings suggest that corosolic acid might be a potential candidate for development of anti-cancer drugs for use in the treatment of leukemia and it would be interesting to determine whether corosolic acid-induced apoptosis has an in vivo role in anticancer activity.

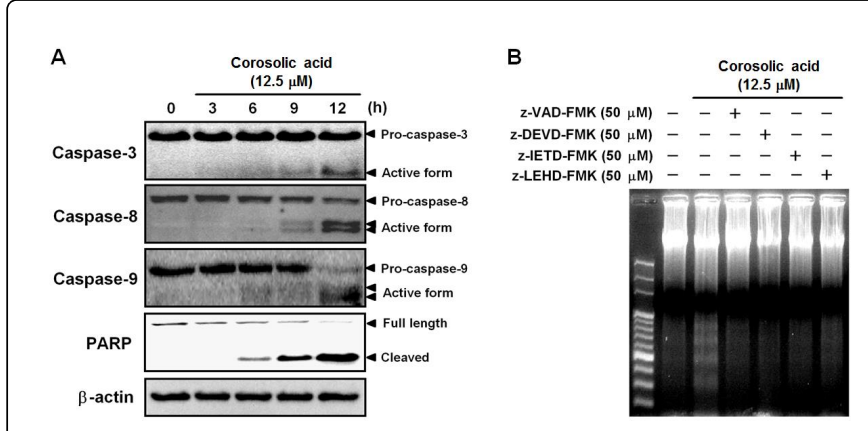

Figure 8: Involvement of the caspase cascade in corosolic acidinduced apoptosis. (A) Effect of corosolic acid on the activation of caspase-3, -8, -9, and PARP cleavage. HL-60 cells were treated with corosolic acid $(12.5 \mu \mathrm{M})$ for the times indicated. The cells were lysed and the caspases, PARP, and $\beta$-actin protein levels were determined by Western blotting. (B) The effect of caspase inhibitors on corosolic acid-induced DNA fragmentation. After pretreatment with $50 \mu \mathrm{M}$ caspase inhibitors for $1 \mathrm{~h}$, HL-60 cells were treated with corosolic acid $(12.5 \mu \mathrm{M})$ for $24 \mathrm{~h}$. DNA fragmentation was analyzed by agarose gel electrophoresis.

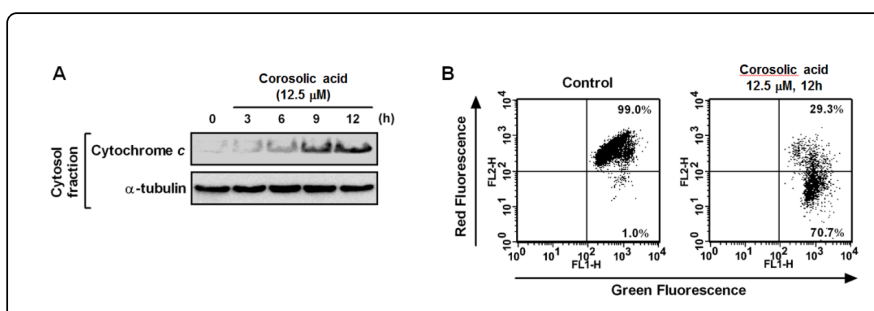

Figure 9: Effect of corosolic acid on mitochondrial dysfunction. (A) Cytochrome $\mathrm{c}$ release into the cytosol after treatment with corosolic acid. HL-60 cells were treated with corosolic acid $(12.5 \mu \mathrm{M})$ for the times indicated and the cytosolic fraction was analyzed to detect cytochrome cby Western blotting. (B) Effect of corosolic acid on the loss of $\Delta \Psi_{\mathrm{m}}$. HL-60 cells were treated with corosolic acid $(12.5 \mu \mathrm{M})$ for the times indicated and analyzed by flow cytometry after staining with JC-1.

\section{Effects of Triterpenes Contained in E. japonica Leaves on Ghrelin}

Ghrelin is an appetite-stimulating peptide hormone which is expressed in stomach and stimulates hypothalamus as shown in Figure 12, with an octanoyl modification at serine 3 that is essential for its orexigenic effect [40]. Ghrelin O-acyltransferase (GOAT) is the enzyme that catalyzes ghrelin acylation using fatty acyl-coenzyme A as a substrate. 
Citation: $\quad$ Takuhiro Uto, Nguyen Huu Tung, Kensuke Nakajima, Tomoe Ohta, Shigeru Oiso, Hiroko Kariyazono and Yukihiro Shoyama (2017) Bioactivities of Eriobotrya japonica (Thunb.) Lindl. Leaf and Its Triterpenes. J Pharmacogn Nat Prod 3: 134. doi: $10.4172 / 2472-0992.1000134$

Page 6 of 9

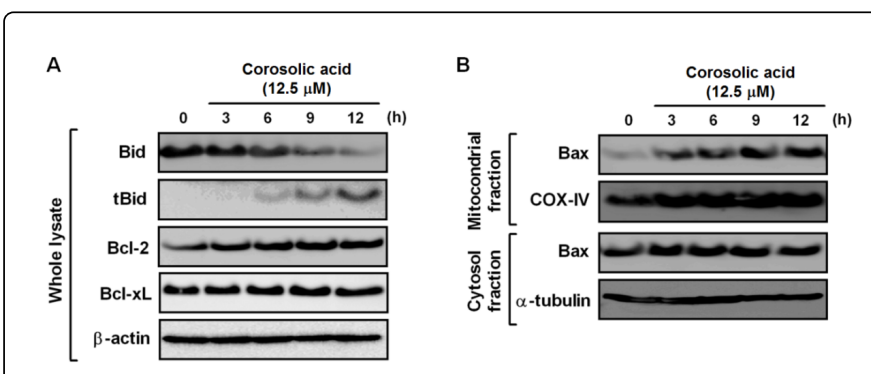

Figure 10: Effect of corosolic acid on Bcl-2 family proteins. HL-60 cells were treated with corosolic acid $(12.5 \mu \mathrm{M})$ for the times indicated. Whole cell lysates (A) and mitochondrial and cytosolic fractions (B) were prepared and the levels of each protein were determined by Western blotting. $\beta$-actin, COX-IV, and $\alpha$-tubulin were used as the loading controls for the whole cell lysate, mitochondrial fraction, and cytosolic fraction, respectively.

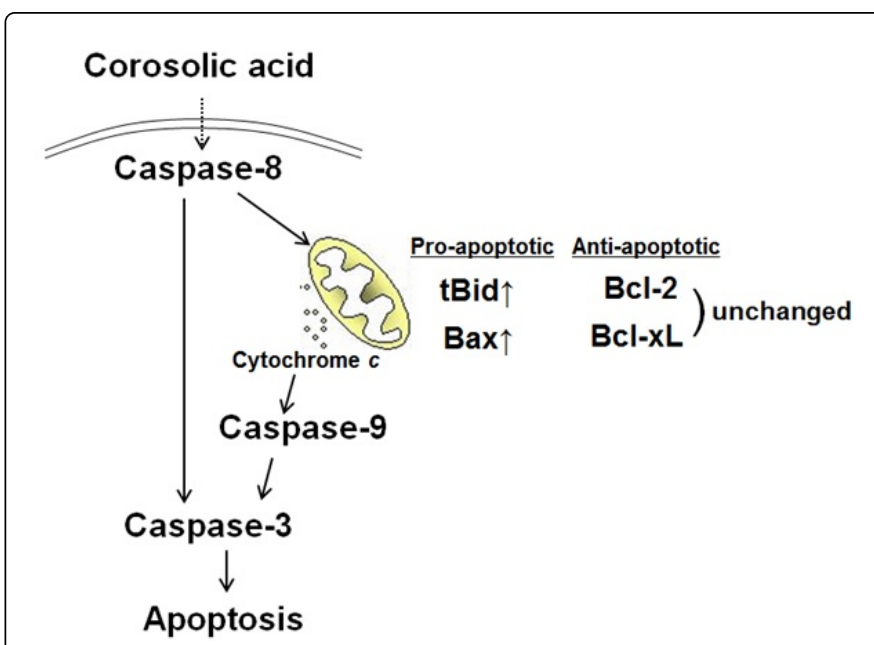

Figure 11: Corosolic acid-induced caspase- 8 activation triggered mitochondrial dysfunction by inducing tBid-mediated Bax activation.

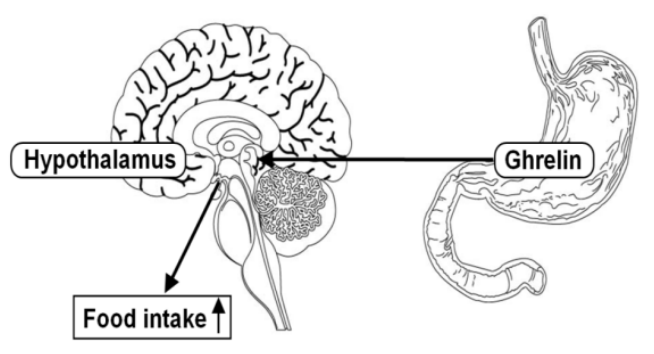

Figure 12: Appetite regulation mechanism of ghrelin.
Our previous study has established the ghrelin-expressing cell line, AGS-GHRL8, by transfecting AGS human gastric carcinoma cells with the human ghrelin gene [41]. AGS-GHRL8 cells expressed both GOAT and furin and produced octanoylated ghrelin in the presence of octanoic acid [41]. As shown in Figure 13, we have developed a cellbased assay system used by AGS-GHRL8 cells to screen for candidate molecules to inhibit octanoylated ghrelin production [41]. We found that fatty acids, such as heptanoic acid, stearic acid, linoleic acid, $\alpha$ linolenic acid, and oleic acid, decreased octanoylated ghrelin levels $[41,42]$. Since GOAT recognizes fatty acyl-coenzyme (Co)A molecules, such as octanoyl-, hexanoyl-, and decanoyl-CoA [43], we speculated that the carboxyl group in a molecule is an important functional group for this inhibitory effect.

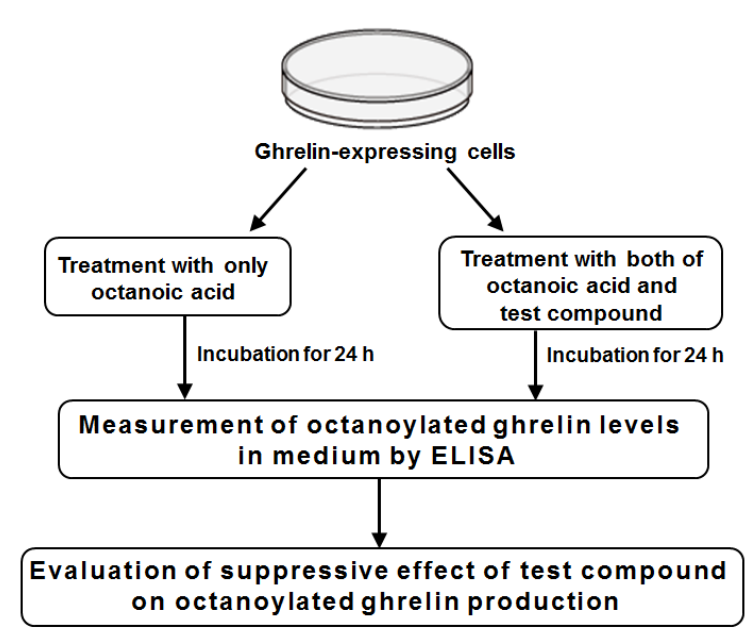

Figure 13: Cell-based assay system for screening or exploration of compounds that inhibit octanoylated ghrelin production.

Triterpenes, such as asiatic acid, betulinic acid, corosolic acid, glycyrrhetinic acid, oleanolic acid, and ursolic acid have shown antiobesity effects in mice fed a high-fat diet [44-49]. Like fatty acids, these triterpenes also have a carboxyl group in their structure, suggesting that they could also suppress octanoylated ghrelin production.

In this section, we showed this possibility in a study by examining the inhibitory effects of the major triterpenes from $E$. japonica leaves on octanoylated ghrelin production in AGS-GHRL8 cells [50]. We also evaluated GOAT and furin mRNA expression in cells treated with triterpenes and the significance of the triterpene carboxyl group in suppressing octanoylated ghrelin production. 
Citation: $\quad$ Takuhiro Uto, Nguyen Huu Tung, Kensuke Nakajima, Tomoe Ohta, Shigeru Oiso, Hiroko Kariyazono and Yukihiro Shoyama (2017) Bioactivities of Eriobotrya japonica (Thunb.) Lindl. Leaf and Its Triterpenes. J Pharmacogn Nat Prod 3: 134. doi: $10.4172 / 2472-0992.1000134$

Page 7 of 9

\section{Triterpenes contained in $E$. japonica leaves suppress octanoylated ghrelin production in ghrelin-expressing human gastric carcinoma cells}

First of all, when we compared oleanolic acid with $\beta$-amyrin, which has the same framework as oleanolic acid except no carboxylic acid (Figure 5), oleanolic acid clearly inhibited the octanoyled ghrelin production (Figure 14A). From this result, we selected triterpenes having carboxylic acid in a molecule. Nest we investigated the effects of corosolic acid, oleanolic acid, and ursolic acid on octanoylated ghrelin production (Figure 14B). Corosolic acid, oleanolic acid, and ursolic acid suppressed octanoylated ghrelin production. In addition, we tested other triterpenes such as asiatic acid, glycyrrhetinic acid, and betulinic acid. The triterpenes tested above have a carboxylic acid group in a molecule similar to fatty acids that we previously reported as having an inhibitory effect on octanoylated ghrelin production $[41,42]$. Therefore, we confirmed that the carboxylic acid group on production of octanoylated ghrelin.

Octanoylated ghrelin stimulates appetite, which can lead to increased body weight [51,52]. We reviewed the inhibitory effects of triterpenes in E. japonica leaves on octanoylated ghrelin production to determine whether these triterpenes can contribute to prevention of obesity.

\section{Conclusion}

The proportions of older people in the populations of many countries have been increasing, which has led to increases in the incidences of several kinds of cancer. Consequently, medical expenses have also been increasing greatly. Additionally, overconsumption of food by many people has increased the prevalence of metabolic syndrome and diabetes. This situation provides justification for promoting increased self-medication using traditional medicines. In this review, we discussed the need to evaluate the bioactivities of $E$. japonica leaf extract and its triterpene constituents to demonstrate the value of E. japonica, which contains higher concentrations of triterpenes, as a traditional medicine that may also have a place in modern medicine.

Triterpenes are biosynthesized from squalene 2,3-oxide and are transferred to several types of triterpene, such as dammaran (ginsenoside), ursan (ursolic acid), oleanan (oleanolic acid), lupan (betulinic acid), and quassinoid types (quassin). Nearly 4000 triterpenes are known and are divided into free types and glycosides or by typically conjugated structures. Although triterpenes are contained in almost all plants and, therefore, are very common, they have a wide spectrum of biological activities, and some may have high potential for use as medicines. For example, a dammaran-type triterpene, ginsenoside Rg3 (Figure 15) isolated from steamed ginseng (red ginseng), was approved in 2003 in China as a new anti-cancer drug

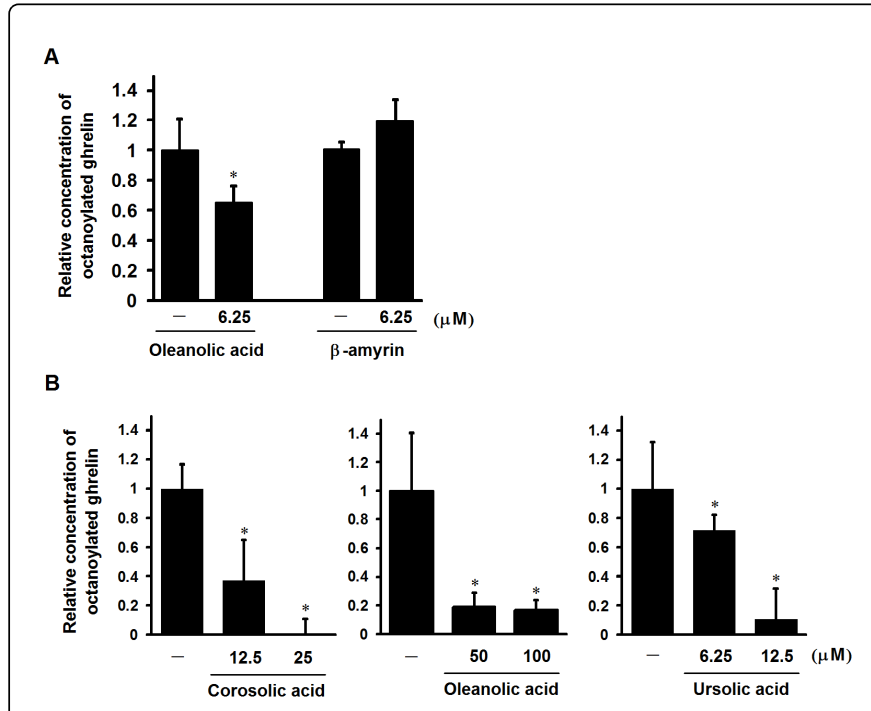

Figure 14: (A) Effect of oleanolic acid and $\beta$-amyrin on octanoylated ghrelin production in AGS-GHRL8 cells. Oleanolic acid but not $\beta$-amyrin suppressed octanoylated ghrelin levels. Octanoic acid was used at $100 \mu \mathrm{M}$. (B) Effect of corosolic acid, oleanolic acid, and ursolic acid on octanoylated ghrelin production in AGS-GHRL8 cells. Data are shown as octanoylated ghrelin concentrations relative to the control. Each value represents mean \pm $\mathrm{SD}(\mathrm{n}=6) .{ }^{*} \mathrm{P}<0.01$ vs. untreated control.

having anti-tumor angiogenesis activity [53]. The activity was supported by the finding that ginsenoside $\operatorname{Rg} 3$ induces apoptosis in human cancer cell lines [54-56]. In this review, we demonstrated that E. japonica leaf extract might provide sufficient bioactivity for use as a traditional anti-inflammatory medicine. Furthermore, because a triterpene, corosolic acid, had the strongest anti-proliferative activity among all of the tested leukemia cell lines but not among normal human skin fibroblast cell lines, corosolic acid is a particularly promising candidate for treatment of leukemia. Using a newly developed assay system, we showed that triterpenes in $E$. japonica suppressed octanoylated ghrelin production in ghrelin-expressing human gastric carcinoma cells, which indicated that $E$. japonica leaves could potentially be used as an anti-obesity dietary supplement. It is well known that the seeds of $E$. japonica contain a cyanide glycoside, amygdarin, that can be used as an anti-cough traditional medicine in Japan [57]. Furthermore, because anti-oxidant activity [58,59] and hepatoprotective activity [60] have been reported, the seeds are also good candidates for health food together with the leaves.

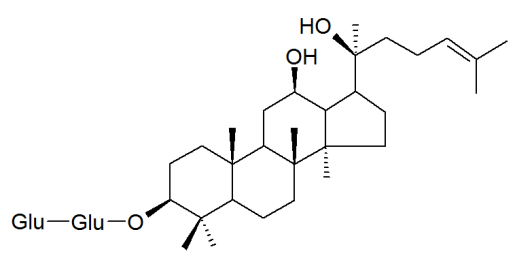

Figure 15: Chemical structure of ginsenoside Rg3. 
Citation: $\quad$ Takuhiro Uto, Nguyen Huu Tung, Kensuke Nakajima, Tomoe Ohta, Shigeru Oiso, Hiroko Kariyazono and Yukihiro Shoyama (2017) Bioactivities of Eriobotrya japonica (Thunb.) Lindl. Leaf and Its Triterpenes. J Pharmacogn Nat Prod 3: 134. doi: $10.4172 / 2472-0992.1000134$

Page 8 of 9

\section{Conflict of Interests}

The authors have declared no conflict of interests.

\section{References}

1. Kawahara N, Satake M, Goda Y (2002) A new acylated flavonol glycoside from the leaves of Eriobotrya japonica. Chem Pharm Bull (Tokyo) 50: 1619-1620.

2. De Tommasi N, De Simone F, Pizza C, Mahmood N, Moore PS, et al (1992) Constituents of Eriobotrya japonica. A study of their antiviral properties. J Nat Prod 55: 1067-1073.

3. Lü H, Chen J, Li WL, Ren BR, Wu JL, et al. (2009) Hypoglycemic and hypolipidemic effects of the total triterpene acid fraction from Folium Eriobotryae. J Ethnopharmacol 122: 486-491.

4. Ge JF, Wang TY, Zhao B, Lv XW, Jin Y, et al. (2009) Anti-inflammatory effect of triterpenoic acids of Eriobotrya japonica (Thunb.) Lindl. leaf on rat model of chronic bronchitis. Am J Chin Med 37: 309-321.

5. Banno N, Akihisa T, Tokuda H, Yasukawa K, Taguchi Y, et al. (2005) Anti-inflammatory and antitumor-promoting effects of the triterpene acids from the leaves of Eriobotrya japonica. Biol Pharm Bull 28: 1995-1999.

6. Ito H, Kobayashi E, Takamatsu Y, Shu-Hua L, Hatano T (2000) Polyphenols from Eriobotrya japonica and their cytotoxicity against human oral tumor cell lines. Chem Pharm Bull (Tokyo) 48: 687-693.

7. Kikuchi T, Akazawa H, Tabata K, Manosroi A, Manosroi J, et al. (2011) 3O-(E)-p-coumaroyl tormentic acid from Eriobotrya japonica leaves induces caspase-dependent apoptotic cell death in human leukemia cell line. Chem Pharm Bull (Tokyo). 59: 78-81.

8. Liu Y, Zhang W, Xu C, Li X (2016) Biological activities of extracts from loquat (Eriobotrya japonica Lindl.): A review. Int J Mol Sci 17: pii:E1983.

9. Zhang Z, Wang CZ, Wen XD, Shoyama Y, Yuan CS (2013) Role of saffron and its constituents on cancer chemoprevention. Pharm Biol 51:920-924.

10. Tung NH, Du GJ, Yuan CS, Shoyama Y, Wang CZ (2013) Isolation and chemopreventive evaluation of novel naphtoquinone compounds from Alkanna tinctoria. Anticancer Drugs 24: 1058-1068.

11. Tung NH, Uto T, Morinaga O, Shoyama Y (2015) Chemical constituents from the aerial parts of Bupleurum falcatum $L$. and biological evidences. Nat Prod Sci 21: 71-75.

12. Tung NH, Uto T, Hai NT, Li G, Shoyama Y (2017) Quassinoids from the root of Eurycoma longifolia and their antiproliferative activity on human cancer cell lines. Pharmacog Mag In press.

13. Tung NH, Suzuki M, Uto T, Morinaga O, Kwofie KD, et al. (2014) Antitrypanosomal activity of diarylheptanoids isolated from the bark of Alnus japonica. Am J Chin Med 42: 1-16.

14. Uto T, Tung NH, Thongjankaew P, Lhieochaiphant S, Shoyama Y (2016) Kayeassamin A Isolated from the flower of Mammea siamensis triggers apoptosis by activating caspase-3/-8 in HL60 human leukemia cells. Pharmacog Res 8: 224-248.

15. Uto T, Tung NH, Fujiki T, Kariyazono H, Kishihara K, et al. (2013) Antiproliferative activities and apoptosis induction by triterpenes derived from Eriobotrya japonica in human leukemia cell lines. Int J Mol Sci 14: 4106-4120.

16. Zhang G, Ghosh S (2000) Molecular mechanisms of NF-囚B activation induced by bacterial lipopolysaccharide through toll-like receptors. J Endotoxin Res 6: 453-457.

17. Fujiwara N, Kobayashi K (2005) Macrophages in inflammation. Curr Drug Targets Inflamm Allergy 4: 281-286.

18. Moncada S, Palmer RM, Higgs EA (1991) Nitric oxide: physiology, pathophysiology, and pharmacology. Pharmacol Rev 43: 109-142.

19. Marletta MA, Yoon PS, Iyengar R, Leaf CD, Wishnok JS (1988) Macrophage oxidation of L-arginine to nitrite and nitrate: nitric oxide is an intermediate. Biochemistry 27: 8706-8711.
20. Weisz A, Cicatiello L, Esumi H (1996) Regulation of the mouse inducibletype nitric oxide synthase gene promoter by interferon-gamma, bacterial lipopolysaccharide and NG-monomethyl-L-arginine. Biochem J 316: 209-215.

21. Clancy RM, Amin AR, Abramson SB (1998) The role of nitric oxide in inflammation and immunity. Arthritis Rheum 41: 1141-1151.

22. Kröncke KD, Fehsel K, Kolb-Bachofen V (1998) Inducible nitric oxide synthase in human diseases. Clin Exp Immunol 113: 147-156.

23. Hempel SL, Monick MM, Hunninghake GW (1994) Lipopolysaccharide induces prostaglandin $\mathrm{H}$ synthase-2 protein and mRNA in human alveolar macrophages and blood monocytes. J Clin Invest 93: 391-396.

24. Hla T, Ristimaki A, Appleby S, Barriocanal JG (1993) Cyclooxygenase gene expression in inflammation and angiogenesis. Ann NY Acad Sci 696: 197-204.

25. Levy GN (1997) Prostaglandin H synthases, nonsteroidal antiinflammatory drugs, and colon cancer. FASEB J 11: 234-247.

26. Uto T, Suangkaew N, Morinaga O, Kariyazono H, Oiso S, Shoyama Y (2010) Eriobotryae folium extract suppresses LPS-induced iNOS and COX-2 expression by inhibition of NF- $\mathrm{BB}$ and MAPK activation in murine macrophages. Am J Chin Med 38: 985-994.

27. Chen F, Demers LM, Shi X (2001) Upstream signal transduction of NFкB activation. Curr Drug Targets Inflamm Allergy 1: 137-149.

28. Zandi E, Rothwarf DM, Delhase M, Hayakawa M, Karin M (1997) The I $\kappa$ B kinase complex (IKK) contains two kinase subunits, IKKa and IKK $\beta$, necessary for IкB phosphorylation and NFkB activation. Cell 91: 243-252.

29. Johnson GL, Lapadat R (2002) Mitogen-activated protein kinase pathways mediated by ERK, JNK, and p38 protein kinases. Science 298: 1911-1912.

30. Uto T, Fujii M, Hou DX (2005) Inhibition of lipopolysaccharide-induced cyclooxygenase-2 transcription by 6-(methylsulfinyl) hexyl isothiocyanate, a chemopreventive compound from Wasabia japonica (Miq.) Matsumura, in mouse macrophages. Biochem Pharmacol 70: 1772-1784.

31. Uto T, Fujii M, Hou DX (2005) 6-(Methylsulfinyl)hexyl isothiocyanate suppresses inducible nitric oxide synthase expression through the inhibition of Janus kinase 2-mediated JNK pathway in lipopolysaccharide-activated murine macrophages. Biochem Pharmacol 70: 1211-1221.

32. Tung NH, Shoyama Y (2012) Eastern blotting analysis and isolation of two new dammarane-type saponins from American ginseng. Chem Pharm Bull (Tokyo) 60: 1329-1333.

33. Shang MY, Tian M, Tanaka H, Li XW, Cai SQ, Shoyama Y (2011) Quality control of traditional Chinese medicine by monoclonal antibody method Curr Drug Discov Technol 8: 60-65.

34. Tanaka H, Fukuda N, Yahara S, Isoda S, Yuan CS, Shoyama Y (2005) Isolation of ginsenoside $\mathrm{Rb} 1$ from Kalopanax pictus by eastern blotting using anti-ginsenoside Rb1 monoclonal antibody. Phytother Res 19: 255-258.

35. Tanaka H, Fukuda N, Shoyama Y (2007) Eastern blotting and immunoaffinity concentration using monoclonal antibody for ginseng saponins in the field of traditional Chinese medicines. J Agric Food Chem 55: $3783-3787$

36. Ulukaya E, Acilan C, Yilmaz Y (2011) Apoptosis: Why and how does it occur in biology? Cell Biochem Funct 29: 468-480.

37. Von Ahsen O, Waterhouse NJ, Kuwana T, Newmeyer DD, Green DR (2000) The 'harmless' release of cytochrome c. Cell Death Differ 7: 1192-1199.

38. Martinou JC, Youle RJ (2011) Mitochondria in apoptosis: Bcl-2 family members and mitochondrial dynamics. Cell 21: 92-101.

39. Crompton M (2000) Bax, Bid and the permeabilization of the mitochondrial outer membrane in apoptosis. Curr Opin Cell Biol 12: 414-419. 
Citation: $\quad$ Takuhiro Uto, Nguyen Huu Tung, Kensuke Nakajima, Tomoe Ohta, Shigeru Oiso, Hiroko Kariyazono and Yukihiro Shoyama (2017) Bioactivities of Eriobotrya japonica (Thunb.) Lindl. Leaf and Its Triterpenes. J Pharmacogn Nat Prod 3: 134. doi: $10.4172 / 2472-0992.1000134$

Page 9 of 9

40. Kojima M, Hosoda H, Date Y, Nakazato M, Matsuo H, et al. (1999) "Ghrelin is a growth-hormone-releasing acylated peptide from stomach. Nature 402: 656-660.

41. Oiso S, Nobe M, Yamaguchi Y, Umemoto S, Nakamura K, Kariyazono H (2013) Establishment of a gastric cell-based assay system for exploring inhibitors of octanoylated ghrelin production. J Biomol Screen 18: 1035-1042.

42. Oiso S, Nobe M, Iwasaki S, Nii W, Goto N, et al. (2015) Inhibitory effect of oleic acid on octanoylated ghrelin production. J Oleo Sci 64: 1185-1192.

43. Ohgusu H, Shirouzu K, Nakamura Y, Nakashima Y, Ida T, et al. (2009) Ghrelin O-acyltransferase (GOAT) has a preference for n-hexanoyl-CoA over n-octanoyl-CoA as an acyl donor. Biochem Biophys Res Commun 386: 153-158.

44. de Melo CL, Queiroz MG, Arruda Filho AC, Rodrigues AM, de Sousa DF, et al. (2009) Betulinic acid, a natural pentacyclic triterpenoid, prevents abdominal fat accumulation in mice fed a high-fat diet. J Agric Food Chem 57: 8776-8781.

45. de Melo CL, Queiroz MG, Fonseca SG, Bizerra AM, Lemos TL, et al. (2010) Oleanolic acid, a natural triterpenoid improves blood glucose tolerance in normal mice and ameliorates visceral obesity in mice fed a high-fat diet. Chem Biol Interact 185, 59-65.

46. Park M, Lee JH, Choi JK, Hong YD, Bae IH, et al. (2014) 18 $\beta$ glycyrrhetinic acid attenuates anandamide-induced adiposity and highfat diet induced obesity. Mol Nutr Food Res 58: 1436-1446.

47. Rao VS, de Melo CL, Queiroz MG, Lemos TL, Menezes DB, et al. (2011) Ursolic acid, a pentacyclic triterpene from Sambucus australis, prevents abdominal adiposity in mice fed a high-fat diet. J Med Food 14: 1375-1382.

48. Yamada K, Hosokawa M, Yamada C, Watanabe R, Fujimoto S, et al. (2008) Dietary corosolic acid ameliorates obesity and hepatic steatosis in KK-Ay mice. Biol Pharm Bull 31: 651-655.

49. Yan SL, Yang HT, Lee YJ, Lin CC, Chang MH, et al. (2014) Asiatic acid ameliorates hepatic lipid accumulation and insulin resistance in mice consuming a high-fat diet. J Agric Food Chem 62: 4625-4631.
50. Nakajima K, Oiso S, Uto T, Morinaga O, Shoyama Y, et al. (2016) Triterpenes suppress octanoylated ghrelin production in ghrelinexpressing human gastric carcinoma cells. Biomed Res 37: 343-349.

51. Nakazato M, Murakami N, Date Y, Kojima M, Matsuo H, et al. (2001) A role for ghrelin in the central regulation of feeding. Nature 409, 194-198.

52. Neary NM, Druce MR, Small CJ, Bloom SR (2006) Acylated ghrelin stimulates food intake in the fed and fasted states but desacylated ghrelin has no effect. Gut 55: 135.

53. Lu P, Su W, Miao ZH, Niu HR, Liu J, et al. (2008) Effect and mechanism of ginsenoside $\mathrm{Rg} 3$ on postoperative life span of patients with non-small cell lung cancer. Chin J Integr Med 14: 33-36.

54. Luo Y, Zhang P, Zeng HQ, Lou SF, Wang DX (2015) Ginsenoside Rg3 induces apoptosis in human multiple myeloma cells via the activation of Bcl-2-associated X protein. Mol Med Rep 12: 3557-3562.

55. Joo EJ, Chun J, Ha YW, Ko HJ, Xu MY, et al. (2015) Novel roles of ginsenoside $\mathrm{Rg} 3$ in apoptosis through downregulation of epidermal growth factor receptor. Chem Biol Interact 233: 25-34.

56. Zhang C, Liu L, Yu Y, Chen B, Tang C, Li X (2012) Antitumor effects of ginsenoside Rg3 on human hepatocellular carcinoma cells. Mol Med Rep 5: 1295-1298.

57. Kimura K, Kimura T (1983) Medicinal Plant in Japan. edt, p.90, Hoikusha Publishing, p:90.

58. Koba K, Matsuoka A, Osada K. Huang YS (2007) Effect of loquat (Eriobotrya japonica) extracts on LDL oxidation. Food Chem 104: 308-316.

59. Yokota J, Takuma D, Hamada A, Onogawa M, Yoshioka S, et al. (2008) Gastroprotective activity of Eriobotrya japonica seed extract on experimentally induced gastric lesions in rats. J Nat Med 62: 96-100.

60. Nishioka Y, Yoshioka S, Kusunose M, Cui T, Hamada A, et al. (2002) Effects of extract derived from Eriobotrya japonica on liver function improvement in rats. Biol Pharm Bull 25: 1053-1057. 